\title{
A flaw in Kripke's modal argument?
}

Kripke states his modal argument against the description theory of names at a number of places (1980: 53, 57, 61, and 74). A full statement in the original text of Naming and Necessity on page 61 is as follows:

The [description theorist] would say that the name is simply defined synonymously, as the cluster of descriptions. It will then be necessary, not that Moses had any particular property in this cluster, but that he had the disjunction of them. There couldn't be any counterfactual situation in which he didn't do any of these things.... Such a suggestion ... must clearly be false.... Most of the things commonly attributed to Aristotle are things Aristotle might not have done at all.

In a nutshell the intended argument is this. All proper names are rigid designators. Any descriptions (at least of contingently existent objects like Moses and Aristotle) which can be at all plausibly thought of as fixing their references, given what the users of the names believe and intend (in the case of Aristotle, descriptions referring to achievements commonly attributed to him) are accidental designators. So such descriptions are not substitutable salva veritate for proper names in modal contexts and hence a fortiori are never synonymous with them.

The response to Kripke's modal argument I shall put forward appeals to the distinction between indicative descriptions, i.e., descriptions formed using indicative verb forms, and what I shall call subjunctive descriptions, descriptions formed using non-indicative verb forms used in subjunctive conditionals. The distinction is between 'the person who is richer than anyone else in the world' and 'the book Mary is reading', on the one hand, and 'the person who would have been richer than anyone else in the world' and 'the book Mary would have been reading' on the other. The 
response is that indicative descriptions are indeed always rigid designators and so do not contrast with proper names. ${ }^{1}$

The distinction is noted by John Burgess (2006: 175). He comments that: ... even when discussing a counterfactual situation in which Bill Gates has given all his wealth to Ivana Trump, it is not unambiguously the case that when we use the description 'the richest person in the world' we must be referring to her and not to him. For the description contains an implicit verb, made explicit in 'the one person to be richer than anyone else in the world'. And this verb is subject to inflection for grammatical mood - 'to be' may become the indicative 'is' or the conditional 'would have been' - in a way that creates a flexibility of reference. Thus 'If Bill Gates had given all his wealth to Ivana, the richest person in the world would have been female' is ambiguous between the truth 'If Bill had given all his wealth to Ivana, the one person who would have been richer than anyone else in the world ... would have been female' and the falsehood 'If Bill had given all his wealth to Ivana, the one person who is richer than anyone else in the world would have been female'. Since the latter is unambiguously false "the one person who is richer than anyone else in the world' designates rigidly. The distinction between the two types of description can be confirmed by noting the difference between the questions 'If Bill had given half his money to Ivana, who would have been the person who would have had more money than anyone else in the world?' and 'If Bill had given half his money to Ivana, who would have been the person who has more money than anyone else in the world?' The answer to the first question may be, say, 'J.K. Rowling' (suppose Bill

\footnotetext{
${ }^{1}$ To insist on the significance of the distinction between subjunctive and indicative verb forms is, of course, not to deny entailments between subjunctive and indicative conditionals. 'If Mary came to the party she would have taken the car. Mary didn't take the car. So Mary didn't come to the party' is valid since the first premiss entails 'if Mary came to the party she took the car'. But it is not an instance of modus tollens.
} 
has 100 billion dollars, J.K. 80, Ivana 20, and no one else is close). The answer to the second question is, trivially, 'Bill'.

For another illustration consider the case of Mary, an elderly Englishwoman, and her elderly English husband Tom. Mary's parents had contemplated emigrating to Australia before her birth. On the balance of probabilities, the following is true:

(1) If Mary's parents had emigrated before her birth, the man she would now have been married to would have been an Australian

as is:

(2) If Mary's parents had emigrated before her birth, the man she is now married to would never have met her.

But the following is false:

(3) If Mary's parents had emigrated before her birth, the man she would now have been married to would never have met her as is:

(4) If Mary's parents had emigrated before her birth, the man she is now married to would have been an Australian.

On the other hand 'if Mary's parents had emigrated before her birth her current husband would have been an Australian' and 'if Mary's parents had emigrated before her birth her current husband would never have met her' are ambiguous, since 'her current husband', like 'the richest man in the world' is a flexible designator. Consequently, 'Mary's current husband might not have been Mary's current husband' is ambiguous. But 'the man Mary is now married to might not have been the man Mary is now married to' is false, whilst 'the man Mary is now married to might not have been the man Mary was now married to' is true, since the man Mary is now 
married to would not have been the man Mary was now married to if her parents had emigrated before her birth.

So it appears that present tense indicative descriptions in English, like the ones given, or, for example, 'the book Mary is now reading' are rigid designators. The same is true of all future tense indicative descriptions, e.g., 'the person who will give the John Locke Lectures in 2150', 'the book Mary will be reading next month'. Past tense descriptions, e.g., 'the book Mary was reading last month', are ambiguous: 'If Mary had joined a different book club, the book Mary was reading last month would not have been have been the book Mary was reading last month', has a true interpretation because the past tense is ambiguous between an indicative and subjunctive reading. This also accounts for the ambiguity of 'If Mary had been sicker on Monday than Jane was on Tuesday ...' (contrast the unambiguous 'If Mary had been sicker on Monday than Jane is today ...' which unambiguously makes a crosscomparison between how things would have been in a counterfactual circumstance and how things are). Past tense descriptions are rigid on the indicative reading. In the case of the rigid present tense description 'the book Mary is now reading' flexibility can be introduced by change to the passive voice and omission of the tensed verb: 'If she had changed book clubs the book now being read by Mary would not have been have been the book now being read by Mary' has a true interpretation (note that the temporal indexical does not impose modal rigidity and can also occur in subjunctive descriptions like 'the man Mary would now have been married to', 'the book Mary would now have been reading'). Hence, in Kripke's terms, 'the book Mary is now reading, if there is such a thing, is the book now being read by Mary' expresses a contingent a priori truth. Insertion of the rigidifying adverb 'actually' to yield 'the book actually being read by Mary now' brings back rigidity. The only descriptions 
which can be non-rigid, then, are ones, like 'Mary's current husband', 'the richest person in the world' and 'the inventor of bifocals', not containing tensed indicative verbs.

If this is correct Kripke's modal argument in Lecture One of Naming and Necessity fails, since rigid descriptions constructed using tensed indicative verbs will always be available, if any descriptions are, as equivalents for proper names.

If this is accepted what is to be the response to the refined Preface version of the modal argument in Naming and Necessity? Here the modal argument goes as follows, adapted to Burgess's example. Suppose I fix the reference of a name 'Richie' by the description 'the person who has more money than anyone else in the world'. Then the simple, non-modal, sentence 'Richie is a female' unambiguously expresses something that could not have been true. On the other hand the simple, non-modal sentence 'the person who has more money than anyone else in the world is a female' does not. Hence the name and description differ in a way that the description theorist cannot accommodate.

But why think that 'Richie is female' unambiguously expresses something that could not have been true? Presumably because Richie is Bill Gates and so it couldn't have been that Richie was female (assuming one's gender is an essential property). But then it couldn't have been that the person who has more money than anyone else in the world was female (though it could have been that the richest person in the world/the person who had more money than anyone else was female, as it would have been if Bill had given all his money to Ivana). And both 'It could have been that Richie is a female' and 'It could have been that the person who has more money than anyone else in the world is a female' are ungrammatical (contrast the grammatical 'It could be that Richie/the person who has more money than anyone else in the world is 
a female'). But, a defender of Kripke's argument may rejoin, is it not the case that with respect to certain counterfactual circumstances, e.g., if Bill Gates had given all his money to Ivana, what 'Richie is a pauper' says would have been true, whereas with respect to those circumstances, what 'the person who has more money than anyone else in the world is a pauper' says would not have been true? But why say that with respect to those circumstances what 'Richie is a pauper' says would have been true? Because it is unambiguously true that if those circumstances had obtained Richie would have been a pauper. But, equally, it is unambiguously true that if those circumstances had obtained the person who has more money than anyone else in the world would have been a pauper, though, of course, it is not the case that if those circumstances had obtained the person who would have had more money than anyone else in the world would have been a pauper. When asked whether what 'Richie is a pauper' says might have been true I answer the question by asking whether it might have been true that Richie was a pauper, i.e., whether there is a way things could have been such that if things had been that way it would have been that Richie was a pauper. When asked whether what 'the person who has more money than anyone else in the world is pauper' says might have been true I answer the question by asking whether it might have been true that the person who has more money than anyone else in the world was a pauper, i.e. whether there is a way things could have been such that if things had been that way it would have been that the person who has more money than anyone else in the world was a pauper. In both cases I must answer affirmatively, though, of course, I acknowledge that there are no ways thing could have been such that if things had been those ways it would have been the case that the person who had more money than anyone else in the world was a pauper.

Consider the following passage (Kripke 1977: 259-60): 
If definite descriptions, $\iota x \varphi(x)$, are taken as primitive and assigned reference, then the conventional non-rigid assignment assigns to such a description, with respect to each possible world, the unique object, if any, which would have $\varphi$ 'd in that world.... For example, 'the number of planets' denotes eight, speaking of a counterfactual situation where there would have been eight planets .... Another type of definite description, $\iota x \varphi x$, a 'rigid' definite description, could be introduced semantically by the following stipulation: let $u x \varphi x$ denote, with respect to all possible worlds, the unique object that (actually) $\varphi$ 's (then 'the number of planets is odd', as interpreted, expresses a necessary truth). Both kinds of definite descriptions can ... be introduced, theoretically, into a single formal language.... Some have suggested that definite descriptions, in English, are ambiguous between the two readings.

Note that in the semantic stipulation for the rigid description Kripke makes use of a merely parenthetical and optional 'actually' and uses a present tense indicative verb form ' $\varphi$ 's'. In the stipulation for the non-rigid description the form 'would have $\varphi$ ' $\mathrm{d}$ ' is used and there is an implicit counterfactual conditional 'would have $\varphi$ ' $\mathrm{d}$ if that world had obtained'. The two stipulations are thus:

$\operatorname{xx} \varphi(x)$ is to denote, with respect to any world $w$, the object which would have $\varphi^{\prime} d$ if $w$ had obtained, $x x \varphi x$ is to denote, with respect to any world $w$, the object which $\varphi$ 's. My contention is that the suggestion that definite descriptions in English are ambiguous between the two readings is partly right. Some are. Descriptions formed from indicative tensed verbs, like 'the person who has more money than anyone else in the world', are unambiguously rigid. But descriptions not containing tensed verbs (unless they are de facto rigid, like 'the square of four'), whether or not they contain 
temporal indexicals (so long as they contain no 'actually' rigidifier), like 'the richest person (at present) in the world', are ambiguous between rigid and non-rigid readings $\left(\right.$ only $^{2}$ in the sense that modal and subjunctive conditional sentences containing them have multiple readings). No descriptions capable of occurring outside subjunctive conditionals (as 'the person who would have had more money than anyone else in the world' is not) are unambiguously non-rigid. Hence there are apparent examples, in Kripke's terms, of contingent a priori truths formed using descriptions alone: 'the person who has more money than anyone else in the world, if there is such a person, is the richest person in the world'; and also examples of necessary a posteriori truths formed using descriptions alone: 'the person who has more money than anyone else in the world is the person who owns more cars than anyone else in the world' (assuming Bill Gates is both), and 'the person who has more money than anyone else in the world is male' (assuming that Bill Gates could not have been female).

Of course, the reply to Kripke's modal argument in this paper only speaks to Kripke's challenge to the descriptivist to come up with descriptions in English which may plausibly thought of as equivalent to proper names, given that such names function as rigid designators. Languages can be imagined, and of course languages actually exist, in which there is no distinction between indicative and subjunctive forms and no descriptions function as required by this response. But it is no part of the descriptivist position to deny the possibility of such languages. This is obviously so since the descriptivist can acknowledge the possibility of a language in which proper

\footnotetext{
${ }^{2}$ To infer anything stronger would be like inferring an ambiguity in 'some man' from the ambiguity of 'some man might have been immortal'. Note that the ambiguities discussed in the text are present here also. 'If the Gods had so decreed, some man would have been immortal' is ambiguous between 'If the Gods had so decreed, something that would have been a man would have been immortal' and 'If the Gods had so decreed, something that is a man would have been immortal' which differ in the powers they ascribe to the Gods. The same ambiguity affects 'If the Gods had so decreed, every man would have been immortal'.
} 
names occur but there are no definite descriptions at all (what Kripke (1977) calls a 'strong Russell language'); indeed, a descriptivist who follows Russell, for whom definite descriptions are a mere abbreviatory convenience, must insist on the possibility of such languages, expressively equivalent to languages in which definite descriptions can be formed. Thus the possibility of such languages is irrelevant to the issue between Kripke and the descriptivists. If definite descriptions formed in English using indicative verb forms are rigid designators it suffices to refute the modal argument since the second premiss of that argument is that no descriptions (at least of contingently existent objects) that can be at all plausibly thought of as synonyms of proper names (leaving aside the additional epistemological and semantic arguments given later in Naming and Necessity) are rigid designators. But indicative descriptions, like 'the book Mary is reading', form an extremely large class of commonplace English expressions and, notwithstanding Kripke's modal argument, are plausibly available to users of proper names as their equivalents.

\section{References}

Burgess, J. 2006 'Saul Kripke Naming and Necessity’ in J. Shand (ed.) Central Works of Philosophy vol. 5. Chesham, Acumen, 166-186

Kripke, S. 1973 'Naming and Necessity’, in D. Davidson and G. Harman (eds.). Semantics of Natural Language. Dordrecht: Reidel, 252-355. Reprinted in revised form as a monograph by Basil Blackwell, Oxford, 1980.

Kripke, S. 1977 'Speaker's reference and semantic reference' Midwest Studies in Philosophy II, 255-276 